\title{
Proposal to unify Clostridium orbiscindens Winter et al. 1991 and Eubacterium plautii (Séguin 1928) Hofstad and Aasjord 1982, with description of Flavonifractor plautii gen. nov., comb. nov., and reassignment of Bacteroides capillosus to Pseudoflavonifractor capillosus gen. nov., comb. nov.
}

\author{
Jean-Philippe Carlier, ${ }^{1} \dagger$ Marie Bedora-Faure, ${ }^{1}$ Guylène K'ouas, ${ }^{1}$ \\ Corentine Alauzet ${ }^{2}$ and Francine Mory ${ }^{2}$
${ }^{1}$ Centre National de Référence des Bactéries Anaérobies et du Botulisme, Institut Pasteur, 25 rue du Dr Roux, F-75724 Paris Cedex 15, France avenue du Maréchal de Lattre de Tassigny, F-54035 Nancy Cedex, France \\ ${ }^{2}$ Centre Hospitalier et Universitaire de Nancy, Hôpital Central, Laboratoire de Bactériologie, 29
}

Correspondence

Francine Mory

f.mory@chu-nancy.fr

\begin{abstract}
We isolated several strains from various clinical samples (five samples of blood, four of intraabdominal pus and one of infected soft tissue) that were anaerobic, motile or non-motile and Gram-positive rods. Some of the strains formed spores. Phylogenetic analysis of the 16S rRNA gene sequence showed that these organisms could be placed within clostridial cluster IV as defined by Collins et al. [(1994). Int J Syst Bacteriol 44, 812-826] and shared more than $99 \%$ sequence similarity with Clostridium orbiscindens DSM $6740^{\top}$ and Eubacterium plautii DSM $4000^{\top}$. Together, they formed a distinct cluster, with Bacteroides capillosus ATCC $29799^{\top}$ branching off from this line of descent with sequence similarities of 97.1-97.4\%. The next nearest neighbours of these organisms were Clostridium viride, Oscillibacter valericigenes, Papillibacter cinnamivorans and Sporobacter termitidis, with sequence similarities to the respective type strains of 93.1-93.4, 91.2-91.4, 89.8-90 and 88.7-89.3\%. On the basis of biochemical properties, phylogenetic position, DNA G $+\mathrm{C}$ content and DNA-DNA hybridization, it is proposed to unify Clostridium orbiscindens and Eubacterium plautii in a new genus as Flavonifractor plautii gen. nov., comb. nov., with the type strain Prévot $S 1^{\top}$ (=ATCC $29863^{\top}=$ VPI $0310^{\top}=\mathrm{DSM}$ $4000^{\top}$ ), and to reassign Bacteroides capillosus to Pseudoflavonifractor capillosus gen. nov., comb. nov., with the type strain CCUG $15402 A^{\top}\left(=\right.$ ATCC $29799^{\top}=$ VPI R2-29-1 ${ }^{\top}$ ).
\end{abstract}

The genus Clostridium has undergone extensive revision in recent years and has been subdivided into 19 clusters on the basis of $16 \mathrm{~S}$ rRNA gene sequence analysis. Cluster I, containing the type species Clostridium butyricum, and clusters XI and XIVa include the majority of pathogenic species (Collins et al., 1994). The members of cluster IV

\section{tDeceased.}

Abbreviation: DPH, 1,6-diphenyl-1,3,5-hexatriene.

The GenBank/EMBL/DDBJ accession numbers for the 16S rRNA gene sequences of strains AIP 162.06, AIP 165.06, AIP 028.07, AIP 201.04 and AIP 029.07 are EU541435-EU541439, respectively.

Results of DPH fluorescence-quenching tests and PCR amplification of spoOA fragments are available as supplementary material with the online version of this paper. exhibit a combination of Clostridium- and non-Clostridiumtype properties and a broad range of chromosomal DNA G + C content (e.g. Clostridium sporosphaeroides, a Grampositive spore-forming rod, and Bacteroides capillosus, a Gram-negative non-sporulating species, with 27 and $60 \mathrm{~mol} \% \mathrm{G}+\mathrm{C}$, respectively). This cluster also includes Clostridium orbiscindens and Eubacterium plautii, species which are asaccharolytic and produce acetate and butyrate. The name Clostridium orbiscindens was proposed for an anaerobic bacillus isolated from human faeces and capable of cleaving the C3-C4 bond of quercetin (Winter et al., 1991) and other flavonoids (Schoefer et al., 2003). This organism is motile, peritrichous, Gram-variable and forms spores.

Eubacterium plautii (type and only known strain Prévot $\mathrm{S1}^{\mathrm{T}}=\mathrm{DSM} 4000^{\mathrm{T}}=$ ATCC $29863^{\mathrm{T}}=$ VPI $0310^{\mathrm{T}}$ ) was 
originally described by Séguin (1928) as Fusobacterium plauti (sic), a motile, Gram-negative, non-spore-forming bacillus. On the basis of electron microscope examination, Hofstad \& Aasjord (1982) showed that Fusobacterium plautii is a non-motile, Gram-positive organism and transferred this species to the genus Eubacterium. However, in Bergey's Manual of Systematic Bacteriology, this organism was described as motile and Gram-negative with very occasional, weakly Gram-positive areas (Moore \& Holdeman Moore, 1986). The ability of Eubacterium plautii to cleave quercetin is not known. Thus, the characteristics and taxonomic status of this species need to be clarified.

The isolation from various clinical samples (five samples of blood, four of intra-abdominal pus and one of infected soft tissue) of several strains with 16S rRNA gene sequences that were phylogenetically closely related to those of Clostridium orbiscindens DSM $6740^{\mathrm{T}}$, Eubacterium plautii DSM $4000^{\mathrm{T}}$ and Bacteroides capillosus ATCC $29799^{\mathrm{T}}$ prompted us to re-evaluate the phylogenetic position of these three species.

Selected isolates AIP 201.04, AIP 162.06 (=LBN 202), AIP $165.06(=\mathrm{LBN} 204)$, AIP $028.07(=\mathrm{LBN} 205)$ and AIP $029.07(=\mathrm{LBN} 206)$ and the three type strains were maintained in trypticase-glucose-yeast extract (TGY) medium (Carlier et al., 2002) under anaerobic conditions at $37{ }^{\circ} \mathrm{C}$ for $24 \mathrm{~h}$ in an anaerobic jar containing $5 \% \mathrm{H}_{2}$, $5 \% \mathrm{CO}_{2}$ and $90 \% \mathrm{~N}_{2}$ (by vol.). $16 \mathrm{~S}$ rRNA gene sequences were determined for each strain as described previously (Carlier et al., 2004). Alignments were done using CLUSTAL $\mathrm{W}$ (Thompson et al., 1994). A distance matrix was calculated by using DNADIST with the Jukes-Cantor parameter (Jukes \& Cantor, 1969). Phylogenetic analysis established that these isolates were part of clostridial cluster IV, as defined by Collins et al. (1994), and were closely related to Clostridium orbiscindens DSM $6740^{\mathrm{T}}$ and Eubacterium plautii DSM $4000^{\mathrm{T}}$, with $99.3-100 \%$ sequence similarity. Together, the latter two type strains and the clinical isolates formed a distinct cluster, with Bacteroides capillosus ATCC $29799^{\mathrm{T}}$ branching off from this line of descent with sequence similarities of 97.1-97.4\% (Fig. 1).
The next nearest neighbours of this cluster were Clostridium viride DSM $6836^{\mathrm{T}}$, Oscillibacter valericigenes Sjm18-20 ${ }^{\mathrm{T}}$, Papillibacter cinnamivorans $\mathrm{CIN}^{\mathrm{T}}$ and Sporobacter termitidis $\mathrm{SYR}^{\mathrm{T}}$, with respective $16 \mathrm{~S}$ rRNA gene sequence similarities of approximately $93,91,90$ and $89 \%$.

The sequences of Clostridium orbiscindens DSM $6740^{\mathrm{T}}$ and Eubacterium plautii DSM $4000^{\mathrm{T}}$ shared $99.7 \%$ similarity. This high similarity suggested that these species may be identical, notwithstanding some physiological differences. To verify this hypothesis, the $\mathrm{G}+\mathrm{C}$ content of the DNA for each strain was determined by HPLC as described by Mesbah et al. (1989) and DNA-DNA hybridization was performed. DNA was extracted using a French pressure cell (Thermo Spectronic) and purified by chromatography on hydroxyapatite as described by Cashion et al. (1977). DNA-DNA hybridization was carried out using the method described by De Ley et al. (1970), modified according to Huß et al. (1983), using a model Cary 100 Bio UV/Vis spectrometer equipped with a Peltier-thermostatted multicell changer and a temperature controller with in-situ temperature probe (Varian). The two type strains shared 72.6-76.9\% DNA-DNA reassociation. The DNA base composition for Eubacterium plautii DSM $4000^{\mathrm{T}}$ and Clostridium orbiscindens DSM $6740^{\mathrm{T}}$ was 61.6 and $58.0 \mathrm{~mol} \% \mathrm{G}+\mathrm{C}$, respectively. Thus, according to the established molecular criteria for species-level relatedness, i.e. strains whose DNAs are at least $70 \%$ related under optimal conditions and whose $16 \mathrm{~S}$ rRNA gene sequences show less than 3\% divergence (Wayne et al., 1987; Stackebrandt et al., 2002), these strains could be regarded as belonging to a single species. Nevertheless, some phenotypic properties were further examined.

\section{Degradation of quercetin}

Bacterial degradation of quercetin was checked by the fluorescence-quenching test according to Schoefer et al. (2001) and modified as follows. Aliquots $(150 \mu \mathrm{l})$ of stock solutions containing $1 \mathrm{mM}$ 1,6-diphenyl-1,3,5-hexatriene (DPH) and $20 \mathrm{mM}$ quercetin were added in loosely covered $180 \times 8 \mathrm{~mm}$ tubes. The tubes contained $5 \mathrm{ml}$

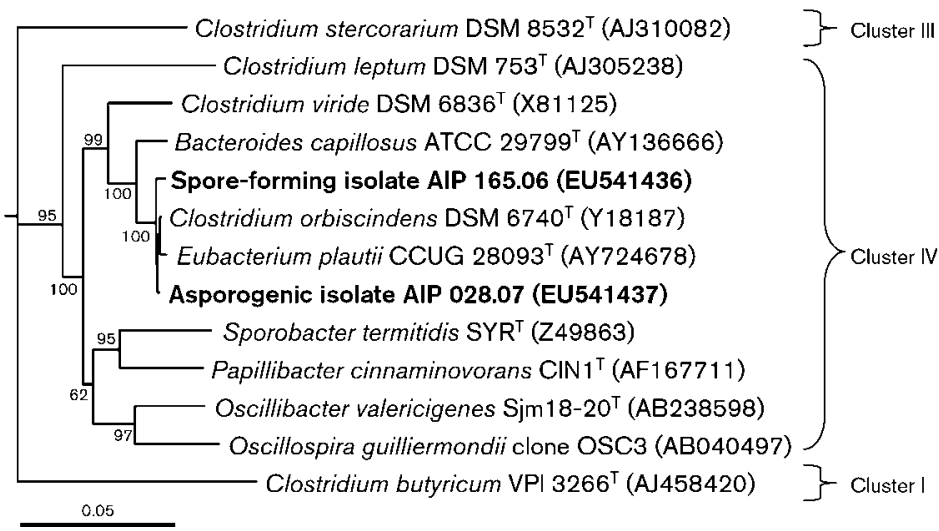

Fig. 1. Dendrogram indicating the phylogenetic positions of Eubacterium plautii, Clostridium orbiscindens and Bacteroides capillosus and closely related species among the clostridial groups. Evolutionary distances (based on 1400 unambiguous nucleotides) were computed by using the neighbour-joining method and bootstrap values calculated from 100 resamplings (Felsenstein, 1993). The sequence of Clostridium butyricum VPI $3266^{\top}$ was used as an outgroup. Bar, $5 \%$ sequence divergence. 
TGY agar and were inoculated with $0.5 \mathrm{ml}$ of an overnight growing culture of each strain and incubated at $37{ }^{\circ} \mathrm{C}$ for $48 \mathrm{~h}$. For detection of fluorescence, the tubes were examined under a UV lamp (wavelength $365 \mathrm{~nm}$ ). Quercetin was degraded by all strains, including Eubacterium plautii DSM $4000^{\mathrm{T}}$, as demonstrated by the strong fluorescence observed (Supplementary Fig. S1, available in IJSEM Online). On the other hand, Escherichia coli $\mathrm{K}-12$, which does not degrade quercetin, and the negative control (without bacteria) did not affect the quenching of DPH fluorescence. Thus, Eubacterium plautii DSM $4000^{\mathrm{T}}$, like Clostridium orbiscindens DSM $6740^{\mathrm{T}}$, is able to degrade quercetin.

\section{Detection of the sporulation-specific gene spo0A}

Spore formation was not observed with some clinical isolates or the type strain of Eubacterium plautii, DSM $4000^{\mathrm{T}}$. However, the inability to form spores is not an effective criterion for the determination of taxonomic status (Cato \& Stackebrandt, 1989). Lack of spore formation may result from defective strains; such asporogenic strains must have the majority of sporulation-specific genes (Onyenwoke et al., 2004). Brill \& Wiegel (1997) described a PCR assay to distinguish asporogenic from non-spore-forming bacteria by employing probes directed against three representative and specific sporulation genes. Thus, we chose to investigate the presence of the sporulation-specific gene spo0A for the strains for which endospores have not been observed. The PCR assay was used with the following modifications: DNA was extracted using the InstaGene Matrix kit (Bio-Rad) as recommended by the manufacturer. PCRs were performed using $1.5 \mathrm{mM} \mathrm{MgCl}_{2}$ instead of $0.125-0.375 \mathrm{mM}$. Our results showed that the isolates for which endospores have not been observed, as well as Eubacterium plautii DSM $4000^{\mathrm{T}}$, exhibited the sporulation-specific gene spo0A (Supplementary Fig. S2).

\section{Cellular fatty acid composition}

Cellular fatty acid composition was analysed by gas chromatography according to Veys et al. (1989) on a fused-silica capillary column $(25 \mathrm{~m} \times 0.25 \mathrm{~mm}$ i.d. $)$ coated with $5 \%$ methyl phenyl silicone. The cellular fatty acid compositions of Eubacterium plautii DSM $4000^{\mathrm{T}}$, Clostridium orbiscindens DSM $6740^{\mathrm{T}}$ and the clinical strains were very similar. All strains contained an unknown compound that eluted between $\mathrm{C}_{12: 0}$ and $\mathrm{C}_{13: 0}$ (6.5$8.2 \%), \mathrm{C}_{14: 0}(34-36.9 \%)$, a second unknown compound that eluted between anteiso- $\mathrm{C}_{15: 0}$ and $\mathrm{C}_{15: 0}(22.6-28.3 \%)$, $\mathrm{C}_{16: 0}(14.4-18.1 \%), \mathrm{C}_{17: 1} \omega 8 c(3.2-5.2 \%)$ and $\mathrm{C}_{18: 0}(3.1-$ $7.3 \%)$ as the major components. Minor fatty acids included iso- $\mathrm{C}_{15: 0}(1.6-2.2 \%)$ and $\mathrm{C}_{16: 1} \omega 9 c(0-3.2 \%)$.

\section{Susceptibility to glycopeptides}

Determination of MICs of vancomycin and teicoplanin according to CLSI standards (CLSI, 2007) showed that all the clinical isolates as well as the type strains of Eubacterium plautii and Clostridium orbiscindens were susceptible to teicoplanin (MICs $0.25-0.5 \mu \mathrm{g} \mathrm{ml}^{-1}$ ) and exhibited reduced susceptibility to vancomycin (MICs 4$8 \mu \mathrm{g} \mathrm{ml}^{-1}$ ). Known glycopeptide-resistance genes were not detected using a PCR assay (Domingo et al., 2005; Fines et al., 1999; McKessar et al., 2000; Mory et al., 1998; Perichon et al., 1997; Rippere et al., 1998).

In conclusion, the phenotypic and genotypic characteristics of Eubacterium plautii and Clostridium orbiscindens were very similar and strongly suggest that the two species represent the same taxon. The only differences observed were the inability of Eubacterium plautii DSM $4000^{\mathrm{T}}$ to produce spores and the motility of Clostridium orbiscindens DSM $6740^{\mathrm{T}}$. These differences were also observed among the clinical isolates and could simply represent strain variations within the species.

Accordingly, we propose that Clostridium orbiscindens Winter et al. 1991 and Eubacterium plautii (Séguin 1928) Hofstad and Aasjord 1982 be unified and reclassified in a new genus, Flavonifractor gen. nov., with Flavonifractor plautii comb. nov. as the type species. Since our clinical isolates share identical properties with Eubacterium plautii and Clostridium orbiscindens, they should be regarded as belonging to the species Flavonifractor plautii.

\section{Taxonomic status of Bacteroides capillosus and Clostridium viride}

Bacteroides capillosus (Tissier 1908) Kelly 1957 is a nonmotile, Gram-negative, non-spore-forming bacillus. Because the original type strain was lost, Cato et al. (1979) selected strain ATCC $29799^{\mathrm{T}}$ as the neotype strain of the species. However, it is evident from tree branching patterns, cellular fatty acids and 5S rRNA sequence studies (Van den Eynde et al., 1989) that Bacteroides capillosus ATCC $29799^{\mathrm{T}}$ is phenotypically and phylogenetically distinct from the genus Bacteroides as defined by Shah \& Collins (1989). In addition, the $\mathrm{G}+\mathrm{C}$ content of the DNA of Bacteroides capillosus (60 mol\%) differs from those of members of the genus Bacteroides, which range between 39 and $48 \mathrm{~mol} \%$ (Shah \& Collins, 1989). Consequently, Bacteroides capillosus cannot be maintained in the genus Bacteroides, and we propose its placement within clostridial cluster IV. The very high level of sequence similarity $(>97 \%)$ together with biochemical and physiological properties and similar DNA base compositions (58 and $61.6 \mathrm{~mol} \% \mathrm{G}+\mathrm{C}$ ) showed that Bacteroides capillosus is closely related to the new genus Flavonifractor (Table 1). However, we tested strain CCUG $15402 \mathrm{~A}^{\mathrm{T}}$ (=ATCC $29799^{\mathrm{T}}$ ) for the presence of the sporulation-specific gene spoOA and for its potential to degrade quercetin. Although this strain has the gene spo0A, it is unable to degrade quercetin (data not shown). This feature and other major differences such as Gram staining and metabolic end products prevent its placement within this genus. In this context, we propose that Bacteroides capillosus be placed in 
Table 1. Comparison of biochemical and physiological properties of Clostridium orbiscindens, Eubacterium plautii, Bacteroides capillosus and Clostridium viride

Data were obtained from this study (Clostridium orbiscindens and Eubacterium plautii), Cato et al. (1979) and Van den Eynde et al. (1989) (Bacteroides capillosus) and Buckel et al. (1994) (Clostridium viride). v, Variable; -, negative; +, positive; NA, no data available. All species are nonfermentative.

\begin{tabular}{|c|c|c|c|c|}
\hline Property & C. orbiscindens & E. plautii & B. capillosus & C. viride \\
\hline Gram staining & $\mathrm{v}$ & $\mathrm{v}$ & - & + \\
\hline $\mathrm{G}+\mathrm{C}$ content $(\mathrm{mol} \%)^{*}$ & 58.0 & 61.6 & 60 & 41.5 \\
\hline Metabolic end products $\dagger$ & A, B & A, B & A, $\mathrm{S}$ & $A, P, B, V$ \\
\hline Major cellular fatty acids & $\mathrm{C}_{14: 0}, \mathrm{C}_{16: 0}$ & $\mathrm{C}_{14: 0}, \mathrm{C}_{16: 0}$ & $\mathrm{C}_{14: 0}, \mathrm{C}_{16: 0}$ & NA \\
\hline
\end{tabular}

${ }^{\star}$ Data for the type strains.

$\dagger$ A, Acetic acid; B, butyric acid; P, propionic acid; s, succinic acid; v, valeric acid.

a new genus, Pseudoflavonifractor gen. nov., as Pseudoflavonifractor capillosus comb. nov.

Phylogenetically, Clostridium viride (Buckel et al., 1994) clearly belongs to cluster IV. However, with sequence similarities of $93.1-93.4 \%$, it is too remote from Flavonifractor or Pseudoflavonifractor to be affiliated with either of these genera. This is supported by a high bootstrap value (Fig. 1). Moreover, Gram staining, DNA base composition ( $41.5 \mathrm{~mol} \% \mathrm{G}+\mathrm{C}$ ) and metabolic end products support the view that this species represents another genus (Table 1). Further investigations are needed to define this probable new genus.

\section{Description of Flavonifractor gen. nov.}

Flavonifractor (Fla.vo.ni.frac'tor. N.L. n. flavonum flavone; L. masc. n. fractor breaker; N.L. masc. n. Flavonifractor flavone-breaker).

Strictly anaerobic bacilli. Cells are Gram-variable after staining. Motility is variable. Spores may or may not be produced, but the sporulation-specific gene spoOA is present. Asaccharolytic; glucose, fructose and ribose can be fermented weakly. Able to cleave quercetin and other flavonoids. Exhibit reduced susceptibility to vancomycin. Major metabolic end products are acetic and butyric acids in TGY broth. Major cellular fatty acids are $\mathrm{C}_{14: 0}$ and $\mathrm{C}_{16: 0}$. Phylogenetically, the genus represents a distinct lineage in clostridial cluster IV. The type species is Flavonifractor plautii.

\section{Description of Flavonifractor plautii comb. nov.}

Flavonifractor plautii (plau'ti.i. N.L. gen. masc. n. plautii of Plaut, named for $\mathrm{H}$. C. Plaut, the bacteriologist who first described this organism).

Basonym: Fusobacterium plautii Séguin 1928.

Other synonyms: Eubacterium plautii (Séguin 1928) Hofstad and Aasjord 1982; Clostridium orbiscindens Winter et al. 1991.
The description combines characteristics of Eubacterium plautii as determined by Séguin (1928) and emended by Hofstad \& Aasjord (1982) and those of Clostridium orbiscindens (Winter et al., 1991). Displays the following characteristics in addition to those given in the genus description. Straight or slightly curved rods, $2-10 \mu \mathrm{m}$ long, and occur singly or in pairs. Some cells are fusiform. Colonies are minute, circular, convex, grey or white, smooth, non-haemolytic on sheep blood agar. Nitrate is not reduced. Production of indole and $\mathrm{H}_{2} \mathrm{~S}$ is variable. Gelatin and meat are not digested. Lecithinase is not produced. The genomic DNA G+C content is 58$61.6 \mathrm{~mol} \%$ (as determined by HPLC). The species includes strains previously classified as Clostridium orbiscindens.

The type strain is DSM $4000^{\mathrm{T}}$ (=ATCC $29863^{\mathrm{T}}=\mathrm{VPI}$ $0310^{\mathrm{T}}=$ Prévot $\mathrm{S}^{\mathrm{T}}$ ). Strains have been isolated from the normal faecal flora, blood, intra-abdominal pus and infected soft tissues in humans.

\section{Description of Pseudoflavonifractor gen. nov.}

Pseudoflavonifractor (Pseu.do.fla.vo.ni.frac'tor. Gr. adj. pseudes false; N.L. masc. n. Flavonifractor a bacterial genus name; N.L. masc. n. Pseudoflavonifractor a false Flavonifractor).

Strictly anaerobic, Gram-negative, non-motile, non-sporeforming bacilli. Phylogenetically, the genus represents a distinct lineage in clostridial cluster IV. The type species is Pseudoflavonifractor capillosus.

\section{Description of Pseudoflavonifractor capillosus comb. nov.}

Pseudoflavonifractor capillosus (ca.pil.lo'sus. L. masc. adj. capillosus full of hair, very hairy).

Basonym: Bacteroides capillosus (Tissier 1908) Kelly 1957.

The phenotypic and morphological characters are as described by Cato et al. (1979) for Bacteroides capillosus. Displays the following properties in addition to those described for the genus. Spores are not formed but the 
sporulation-specific gene spoOA is present. Straight or curved rods, 1.6-7.1 $\mu \mathrm{m}$ long, predominantly regular in shape, arranged singly, in pairs or in short chains. Filaments with tapered ends are observed. Surface colonies on 48-h-old, anaerobic blood agar are pinpoint to $0.5 \mathrm{~mm}$ in diameter, circular, slightly erose, colourless, translucent and slightly peaked. Growth is stimulated by the addition of approx. $0.02 \%$ Tween 80 but is inhibited by $20 \%$ bile. Good growth is observed at 37 and $45{ }^{\circ} \mathrm{C}$. Asaccharolytic; glucose, cellobiose, fructose, galactose, lactose, maltose, mannose, starch and sucrose can be fermented weakly. Aesculin is hydrolysed. Nitrate is not reduced. Indole is not produced. $\mathrm{H}_{2} \mathrm{~S}$ is usually not produced. Gelatin is usually not digested. Lecithinase and lipase are not produced. Unable to cleave quercetin. Acetic and succinic acids are detected after culture in TGY broth. The major cellular fatty acids are $\mathrm{C}_{14: 0}$ and $\mathrm{C}_{16: 0}$. The $\mathrm{G}+\mathrm{C}$ content of the DNA of the type strain is $60 \mathrm{~mol} \%$.

The type strain ATCC $29799^{\mathrm{T}}\left(=\right.$ CCUG $15402 \mathrm{~A}^{\mathrm{T}}=\mathrm{VPI}$ $\mathrm{R} 2-29-1^{\mathrm{T}}$ ) was isolated from human faeces.

\section{Acknowledgements}

We thank Jean Euzéby for his advice on etymology and Enevold Falsen (CCUG, University of Göteborg, Sweden) for the gift of Bacteroides capillosus CCUG $15402 \mathrm{~A}^{\mathrm{T}}$.

\section{References}

Brill, J. A. \& Wiegel, J. (1997). Differentiation between spore-forming and asporogenic bacteria using a PCR and Southern hybridization based method. J Microbiol Methods 31, 29-36.

Buckel, W., Janssen, P. H., Schuhmann, A., Eikmanns, U., Messner, P., Sleytr, U. \& Liesack, W. (1994). Clostridium viride sp. nov., a strictly anaerobic bacterium using 5-aminovalerate as growth substrate, previously assigned to Clostridium aminovalericum. Arch Microbiol 162, 387-394.

Carlier, J. P., Marchandin, H., Jumas-Bilak, E., Lorin, V., Henry, C., Carriere, C. \& Jean-Pierre, H. (2002). Anaeroglobus geminatus gen. nov., sp nov., a novel member of the family Veillonellaceae. Int J Syst Evol Microbiol 52, 983-986.

Carlier, J. P., K’ouas, G., Bonne, I., Lozniewski, A. \& Mory, F. (2004). Oribacterium sinus gen. nov., sp. nov., within the family 'Lachnospiraceae' (phylum Firmicutes). Int J Syst Evol Microbiol 54, 1611-1615.

Cashion, P., Holder-Franklin, M. A., McCully, J. \& Franklin, M. (1977). A rapid method for the base ratio determination of bacterial DNA. Anal Biochem 81, 461-466.

Cato, E. P. \& Stackebrandt, E. (1989). Taxonomy and phylogeny. In Clostridia: Biotechnology Handbook, pp. 1-22. Edited by N. P. Minton \& D. J. Clarke. London: Plenum Press.

Cato, E. P., Holdeman, L. V. \& Moore, W. E. C. (1979). Proposal of neotype strains for seven non-saccharolytic Bacteroides species. Int $J$ Syst Bacteriol 29, 427-434.

CLSI (2007). Methods for antimicrobial susceptibility testing of anaerobic bacteria. Approved standard M11-A7. Wayne, PA: Clinical and Laboratory Standards Institute.

Collins, M. D., Lawson, P. A., Willems, A., Cordoba, J. J., FernandezGarayzabal, J., Garcia, P., Cai, J., Hippe, H. \& Farrow, J. A. E. (1994)
The phylogeny of the genus Clostridium: proposal of five new genera and eleven new species combinations. Int J Syst Bacteriol 44, 812-826.

De Ley, J., Cattoir, H. \& Reynaerts, A. (1970). The quantitative measurement of DNA hybridization from renaturation rates. Eur $J$ Biochem 12, 133-142.

Domingo, M. C., Huletsky, A., Giroux, R., Boissinot, K., Picard, F. J., Lebel, P., Ferraro, M. J. \& Bergeron, M. G. (2005). High prevalence of glycopeptide resistance genes $\operatorname{van} B, \operatorname{van} D$, and $\operatorname{van} G$ not associated with enterococci in human fecal flora. Antimicrob Agents Chemother 49, 4784-4786.

Felsenstein, J. (1993). PHYLIP (phylogeny inference package) version 3.5c. Distributed by the author. Department of Genome Sciences, University of Washington, Seattle, USA.

Fines, M., Perichon, B., Reynolds, P., Sahm, D. F. \& Courvalin, P. (1999). vanE, a new type of acquired glycopeptide resistance in Enterococcus faecalis BM4405. Antimicrob Agents Chemother 43, 21612164.

Hofstad, T. \& Aasjord, P. (1982). Eubacterium plautii (Séguin 1928) comb. nov. Int J Syst Bacteriol 32, 346-349.

Huß, V. A. R., Festl, H. \& Schleifer, K. H. (1983). Studies on the spectrometric determination of DNA hybridization from renaturation rates. Syst Appl Microbiol 4, 184-192.

Jukes, T. H. \& Cantor, R. R. (1969). Evolution of protein molecules. In Mammalian Protein Metabolism, vol. 3, pp. 21-132. Edited by H. N. Munro. New York: Academic Press.

Kelly, C. D. (1957). Genus I. Bacteroides Castellani and Chalmers, 1919. In Bergey's Manual of Determinative Bacteriology, 7th edn, pp. 424-436. Edited by R. S. Breed, E. G. D. Murray \& N. R. Smith. London: Baillière, Tindall \& Cox.

McKessar, S. J., Berry, A. M., Bell, J. M., Turnidge, J. D. \& Paton, J. C. (2000). Genetic characterization of $v a n G$, a novel vancomycin resistance locus of Enterococcus faecalis. Antimicrob Agents Chemother 44, 3224-3228.

Mesbah, M., Premachandran, U. \& Whitman, W. (1989). Precise measurement of the $\mathrm{G}+\mathrm{C}$ content of deoxyribonucleic acid by high performance liquid chromatography. Int J Syst Bacteriol 39, 159-167.

Moore, W. E. C. \& Holdeman Moore, L. V. (1986). Genus Eubacterium Prévot 1938, 294 ${ }^{\mathrm{AL}}$. In Bergey's Manual of Systematic Bacteriology, vol. 2, pp. 1353-1373. Edited by P. H. A. Sneath, N. S. Mair, M. E. Sharpe \& J. G. Holt. Baltimore: Williams \& Wilkins.

Mory, F., Lozniewski, A., David, V., Carlier, J. P., Dubreuil, L. \& Leclercq, R. (1998). Low-level vancomycin resistance in Clostridium innocuum. J Clin Microbiol 36, 1767-1768.

Onyenwoke, R. U., Brill, J. A., Farahi, K. \& Wiegel, J. (2004). Sporulation genes in members of the low G + C Gram-type-positive phylogenetic branch (Firmicutes). Arch Microbiol 182, 182-192.

Perichon, B., Reynolds, P. \& Courvalin, P. (1997). vanD-type glycopeptide-resistant Enterococcus faecium BM4339. Antimicrob Agents Chemother 41, 2016-2018.

Rippere, K., Patel, R., Uhl, J. R., Piper, K. E., Steckelberg, J. M., Kline, B. C., Cockerill, F. R., III \& Yousten, A. A. (1998). DNA sequence resembling van $A$ and $v a n B$ in the vancomycin-resistant biopesticide Bacillus popilliae. J Infect Dis 178, 584-588.

Schoefer, L., Braune, A. \& Blaut, M. (2001). A fluorescence quenching test for the detection of flavonoid transformation. FEMS Microbiol Lett 204, 277-280.

Schoefer, L., Mohan, R., Schwiertz, A., Braune, A. \& Blaut, M. (2003). Anaerobic degradation of flavonoids by Clostridium orbiscindens. Appl Environ Microbiol 69, 5849-5854.

Séguin, P. (1928). Culture du Fusobacterium plauti, forme mobile du bacille fusiforme. C R Seances Soc Biol 99, 439-442 (in French). 
Shah, H. N. \& Collins, M. D. (1989). Proposal to restrict the genus Bacteroides (Castellani and Chalmers) to Bacteroides fragilis and closely related species. Int J Syst Bacteriol 39, 85-87.

Stackebrandt, E., Frederiksen, W., Garrity, G. M., Grimont, P. A. D., Kämpfer, P., Maiden, M. C. J., Nesme, X., Rosselló-Mora, R., Swings, J. $\&$ other authors (2002). Report of the ad hoc committee for the reevaluation of the species definition in bacteriology. Int J Syst Evol Microbiol 52, 1043-1047.

Thompson, J. D., Higgins, D. G. \& Gibson, T. J. (1994). Clustal W: improving the sensitivity of progressive multiple sequence alignment through sequence weighting, position-specific gap penalties and weight matrix choice. Nucleic Acids Res 22, 4673-4680.

Tissier, H. (1908). Recherche sur la flore intestinale normale des enfants âgés d'un an à cinq ans. Ann Inst Pasteur (Paris) 22, 189-208 (in French).

Van den Eynde, H., De Baere, R., Shah, H. N., Gharbia, S. E., Fox, G. E., Michalik, J., Van de Peer, Y. \& De Wachter, R. (1989). 5S ribosomal ribonucleic acid sequences in Bacteroides and Fusobacterium: evolutionary relationships within these genera and among eubacteria in general. Int J Syst Bacteriol 39, 78-84.

Veys, A., Callewaert, W., Waelkens, E. \& Van den Abbeele, K. (1989). Application of gas-liquid chromatography to the routine identification of nonfermenting Gram-negative bacteria in clinical specimens. J Clin Microbiol 27, 1538-1542.

Wayne, L. G., Brenner, D., Colwell, R. R., Grimont, P. A. D., Kandler, O., Krichevsky, M. I., Moore, L. H., Moore, W. E. C., Murray, R. G. E. \& other authors (1987). Report of the ad hoc committee on reconciliation of approaches to bacterial systematics. Int $J$ Syst Bacteriol 37, 463-464.

Winter, J., Popoff, M. R., Grimont, P. \& Bokkenheuser, V. D. (1991). Clostridium orbiscindens sp. nov., a human intestinal bacterium capable of cleaving the flavonoid C-ring. Int J Syst Bacteriol 41, 355357. 